\title{
EL ENTENDIMIENTO AGENTE SEGÚN TOMÁS DE AQUINO
}

\author{
Juan Fernando Sellés \\ Universidad de Navarra
}

\begin{abstract}
RESUMEN
El intelecto agente es la cumbre de la teoría del conocimiento humano según Tomás de Aquino. Es personal en cada hombre; uno con el ser de cada persona humana; separado del cuerpo, sin mezcla con él; impasible y siempre en acto; luz cognoscitiva innata. Procede directamente de Dios, y de su Luz participa tanto natural como sobrenaturalmente, y esto último, tanto en la presente situación (lumen fidei) como en la futura (lumen gloriae). Gracias a él somos libres y responsables, y por ello es condición de posibilidad de la ética y política. Permite conocer todo, porque activa las distintas facultades cognoscitivas humanas. Usa los hábitos cognoscitivos innatos como de instrumentos. Es perpetuo, pero tras esta vida no conocerá como ahora conoce.
\end{abstract}

Palabras clave: Tomás de Aquino, entendimiento agente, lumen gloriae, lumen fidei.

\begin{abstract}
The «intellectus agens» is the zenith of the theory of the human knowledge according to Saint Thomas Aquinas. It is personal in each human being: one with the being of the human person. Separated from the body, without mixture with it, impassible and always in act. Innate cognoscitive light. It proceeds from God, and from Him it participates natural and supernaturally. Through the «intellectus agens» we are free and responsible. It permits to know everything, because it activates the different human cognoscitive faculties. It uses the innate habits as instruments. It is perpetual, but after this life it will no know as now.
\end{abstract}

Key words: Thomas Aquinas, active intellect, lumen gloriae, lumen fidei.

\section{INTRODUCCIÓN}

El entendimiento agente es el tema de mayor alcance de la teoría del conocimiento humano. Descubrimiento netamente aristotélico, es la clave de la bóveda de la gnoseología del Filósofo, y es, asimismo, el tema de mayor alcance de la epistemología humana según Tomás de Aquino.

Como es sabido, Aristóteles descubre la distinción real entre acto y potencia que se da en toda la realidad salvo en el Acto Puro. Pero si esa distinción se mantiene en todo el ámbito de lo real salvo en Dios, el conocimiento humano no puede permanecer al margen de ella, puesto que el conocer humano también es real. En efecto, el Estagirita descubre una potencia susceptible de conocer todas las cosas a la que llama entendimiento posible, que inicialmente es pura potencia de conocer sin conocimiento innato ninguno (tamquam tabula rasa), y un conocer en acto, asimismo inorgánico, requerido para activar a dicha potencia nativamente $p a-$ siva. Este conocer activo además de ser en acto desde que es, debe ser previo, superior y perfectamente adaptado a la potencia cognoscitiva de índole espiritual. Se trata del intelecto agente. 
Pero, como se recordará, para Tomás de Aquino todavía existe una distinción real superior en todo lo creado a la que media entre acto y potencia, a saber, la de acto de ser y esencia. Pero si esa distinción afecta a toda la realidad salvo al Creador, entonces se dará inexorablemente también en el conocimiento humano. Pero si es así, ¿qué actúa como acto de ser y qué como esencia en el conocer humano? Tomás de Aquino responde que «el intelecto agente será uno según el ser con el hombre. Pero no según el ser accidental: puesto que ya no sería el entendimiento agente sustancia, sino accidente... Queda, pues, que el intelecto agente sea uno con el hombre según el ser sustancial» ${ }^{1}$. Pero si el intelecto agente está en el orden del ser humano (esse hominis), en consecuencia, el entendimiento posible debe pertenecer a la esencia humana (essentia).

Pues bien, lo que se pretende rastrear en esta investigación es si en el corpus tomista hay suficiente base textual para hacer equivalente el intellectus agens al esse hominis. El enfoque, como se puede apreciar, no es sólo de teoría del conocimiento sino de antropología. Y aunque la orientación fuese sólo cognoscitiva, valdría la pena abordarla, puesto que si el intelecto agente es la cumbre de la teoría, entendida ésta en sentido clásico, a saber, como visión o contemplación, ha sido poco tenido en cuenta en la historia del pensamiento. Efectivamente, salvo los comentadores aristotélicos del periodo de esplendor de la Edad Media y a excepción de los tomistas de las diversas épocas posteriores, este tema no se encuentra en los grandes forjadores de la filosofía moderna y contemporánea.

Tampoco es, a pesar de su relevancia, uno de los temas filosóficos de mayor frecuencia de aparición en el corpus tomista ${ }^{2}$. Con todo, es una cuestión más importante que las más recurrentes porque, además de ocupar la cumbre del conocimiento humano, es la cima de la antropologia, y la instancia humana que se corresponde con la felicidad. Si para Aristóteles, y asimismo para Tomás de Aquino, la teoría es la forma más alta de vida ${ }^{3}$, el acto humano que equivale a la cumbre del saber es el intelecto agente.

Tomás de Aquino trató de este tema, al margen de otras referencias sueltas y esporádicas, en 9 escritos relevantes, que por orden cronológico son: el Comentario a las Sentencias ${ }^{4}$ (125256), las Cuestiones Disputadas sobre la Verdad (1256-59), varios lugares de la Suma Contra los Gentiles ${ }^{6}$ (1259-65), las Cuestiones Disputadas sobre el Alma ${ }^{7}$ (1265-66), el Compendio de Teología ${ }^{8}$ (1267), las Cuestiones Disputadas Sobre las Criaturas Espirituales ${ }^{9}$ (1267-68), el Comentario al libro III Sobre el Alma ${ }^{10}$ (1267-68), el opúsculo Sobre la Unidad del Intelecto $^{11}$ contra los averroistas (1279), y la Suma Teológica ${ }^{12}$ (1273). Vamos a seguir en nuestra exposición de la doctrina tomista este orden cronológico.

1 Summa Contra Gentes, 1. III, cap. 42 , n. 7.

2 La voz «intellectus agens» aparece sólo 895 veces en el Index Thomisticus confeccionado merced al equipo dirigido por ROBERTO BuSA en colaboración con IBM. Los temas más recurrentes del Index pasan de las 20.000 apariciones; los medios, las 10.000, y al grupo de los escasos pertenecen los términos que quedan por debajo de las 1.000 veces.

3 Cfr. ARISTóteles, Ética a Nicómaco, 1. X, cap. 7 (BK 1178 a 6-7). Cfr. el comentario de ToMás DE AQUINo a este pasaje.

4 In II Sententiarum, d. 17, q. 2, a. 1.

$5 \quad$ Q.D. De Veritate, q. 10 , a. 6.

6 Summa Contra Gentes, 1. II, caps. 76, 77 y 78; 1. III, caps. 42, 43, 44 y 45.

7 Q.D. De Anima, qq. 4 y 5.

8 Compendium Theologiae, lb. I, cap. 83.

9 Q.D. De Spiritualibus Creaturis, q. un., a. 10.

10 In De Anima, 1. III, cap. 10.

11 De Unitate Intellectus, caps. I-V.

12 Summa Theologiae, I ps., q. 79, aa. 3, 4 y 5. 


\section{EL INTELECTO AGENTE EN EL COMENTARIO A LAS SENTENCIAS DE PEDRO LOMBARDO}

En el Comentario a las Sentencias se declara que tanto el entendimiento agente como el posible son dos potencias distintas: «es imposible que el agente y el posible no sean diversas potencias... De modo que el alma tiene una virtud por la que hace a las especies sensibles ser inteligibles en acto, que es el intelecto agente; y tiene una virtud por la cual está en potencia..., y esta virtud o potencia se llama intelecto posible» ${ }^{13}$.

Ambas potencias son distintas para cada hombre. El entendimiento agente es acto respecto del posible. Ambos empiezan a existir con el cuerpo. Pero el intelecto es acto del cuerpo en un sentido distinto (principio finito) a como es acto de las operaciones cognoscitivas (principio infinito). Por lo demás, se añade que el que requiere de hábitos, tanto adquiridos, como innatos e infusos, es el entendimiento posible, no el agente ${ }^{14}$.

Estas tesis contrarrestan las aporías árabes de la unicidad de entendimiento agente o posible para el género humano, pero plantean algunos problemas: a) ¿Cómo es posible que el entendimiento agente sea, en sentido estricto, una «potencia» si está en acto desde el comienzo? b) ¿Cómo se puede admitir que los hábitos innatos inhieran en el entendimiento posible si «hábito» significa perfección, esto es, acto, y el posible nativamente es tamquam tabula rasa, a saber, pura potencia? Estas dudas sobre el entendimiento agente serán, como tendremos ocasión de comprobar, un pesado lastre a lo largo de las investigaciones posteriores de Tomás de Aquino hasta el final de su producción.

\section{EL INTELECTO AGENTE EN LAS CUESTIONES DISPUTADAS DE VERITATE}

Comienza el De Veritate advirtiéndonos de que sin el intelecto agente el hombre no puede conocer nada ${ }^{15}$. Esto es buen comienzo, porque este intelecto es el origen de todo conocer humano, fuente ínsita en el propio hombre. A continuación Tomás de Aquino recuerda que el papel del intelecto agente es el de abstraer de lo sensible ${ }^{16}$. Añade también que por él conocemos todo lo que podemos conocer ${ }^{17}$.

Más adelante mantiene las siguientes tesis centrales sobre el intelecto agente: 1) El entendimiento agente hace a los inteligibles en potencia inteligibles en acto ${ }^{18}$. Por tanto, su co-

13 In II Sententiarum, d. 17, q. 2, a. 1, co/277-320.

14 «Intellectus possibilis qui de se est indeterminatus, sicut materia prima, habitu indiget, quo participet rectitudinem suae regulae: et naturali quantum ad ea quae ex naturali lumine intellectus agentis, qui est eius regula, statim determinatur, sicut sunt prima principia; et acquisitio, quantum ad ea quae ex his principiis educi possunt; et infuso, quo participat rectitudinem primae regulae in his quae intellectum agentem excedunt», In III Sententiarum, $\mathrm{d}$. 23 , q. 1 , a. $1, \mathrm{co} / 80$.

15 «Sin el intelecto agente nada podría el hombre entenden, De Veritate, q. 1, a. 1.

16 «Formam sensibilem, quae lumine intellectus agentis est a sensibilibus abstracta», De Veritate, q. 8, a. 3, co/65. Cfr. también: De Veritate, q. 18, a. 2, co/36. «Intellectus potest abstrahendo pervenire ad quiditatem rei materialis non habentem aliam quiditatem; quam quidem intelligere potest, quia eam a phantasmatibus abstrahit et est facta intelligibilis per lumen intellectus agentis», De Veritate, q. 18, a. 5, ad 6/5.

17 «Anima secundum potentiam naturalem non se extendit ad plura intelligibilia quam ad ea quae possunt manifestari per lumen intellectus agentis», De Veritate, q. 8, a. 4, ad 4. Ello implica que, por ejemplo, los actos y los hábitos de la inteligencia, que ni son sensibles ni derivan del conocimiento sensible, también los ilumina el entendimiento agente directa o indirectamente.

18 \&er intellectum agentem possit facere phantasmata intelligibila in actu, quae sunt potentia intelligibilia, et per intellectum possibilem recipere species intelligibiles sic abstractas», De Veritate, q. 19, a. 1, co/172. 
nocimiento no puede tener como tema lo que es previamente en acto $^{19} .2$ ) Es acto respecto del intelecto posible. 3) Su luz es originaria en nosotros y proviene de Dios: «la luz del intelecto agente..., procede en el alma, sin duda, como del primer origen, de las sustancias separadas y principalmente de Dios. Y según esto, es verdad que nuestra mente toma la ciencia de los sensibles... Y así también, en la luz del intelecto agente está introducida en cierto modo en nosotros nativamente toda ciencia originalmente, mediante las concepciones universales, que son conocidas inmediatamente por la luz del intelecto agente, por las cuales como por principios universales juzgamos de lo demás, y lo conocemos previamente en ellos» ${ }^{20}$. 4) Se corresponde con los hábitos innatos y con sus temas, por ejemplo, los primeros principios ${ }^{21}$. Pero él carece de hábitos ${ }^{22}$. 5) Es superior al posible ${ }^{23}$. 6) Por lo demás, Tomás de Aquino también vincula en esta obra, de alguna manera, el intelecto agente al acto de ser humano ${ }^{24}$.

El De Veritate también ofrece problemas abiertos respecto de los que no se encuentra solución en estas páginas. Por ejemplo: 1) ¿Por qué los hábitos nativos no pueden inherir en el entendimiento agente? 2) ¿Cuál es el «objeto» del entendimiento agente, es decir, su tema, porque es claro que un conocer sin tema es absurdo? 3) ¿El intelecto agente es, en sentido estricto, una «potencia»? 4) ¿Es acto también respecto de la voluntad? Veamos si en escritos posteriores se alumbran soluciones a estas dificultades.

Cronológicamente, el Comentario al De Trinitate de Boecio (1257-59) es contemporáneo al De Veritate (1256-59). Se trata de uno de los mejores y más sintéticos tratados de teoría del conocimiento humano de la historia de la filosofía, sólo equiparable al De Anima de Aristóteles. Pero a pesar de ocupar en él el entendimiento agente la clave del arco cognoscitivo, en este resumen de gnoseología tomista apenas hay breves referencias a él.

Las sentencias que allí mantiene Tomás de Aquino son: 1) El entendimiento agente hace inteligibles en acto las formas abstraídas de la fantasía, pero no las formas separadas, a las que

19 «ntellectus possibilis naturaliter non est in potentia ut in eo fiant nisi ea quae intellectus agens natus est facere... Actione autem intellectus agentis non fiunt intelligibilia ea quae sunt de seipsis intelligibilia, cuiusmodi sunt essentiae angelorum, sed esa quae sunt de seipsis in potentia intelligibilia, qualia sunt essentiae rerum materialium, quae per sensum et imaginationem capiuntur», De Veritate, q. 18, a. $5, \mathrm{co} / 28$.

20 De Veritate, q. 10, a. 6, co/ 120.

21 «ic igitur principium naturalis humanae cognitionis est esse quidem in potentia ad omnia cognoscibilia, non habere autem a principio notitiam nisi eorum quae statim per lumen intellectus agentis cognoscuntur, sicut sunt prima principia universalia», De Veritate, q. 18, a. 7, co/70. Y más adelante: «intellectus agens est quo est omnia facere. Haec autem sunt quae a phantasmatibus abstrahuntur, et in quorum cognitionem devenire possumus per principia naturaliter cognitas, De Veritate, q. 20, a. 6, ad 2/7.

22 «Non oportet quod si intellectus agens non indiget habitu quod intellectus possibilis habitu non indigeat. Quod enim intellectus agens habitu non indigeat ad suam operationem, ex hoc contingit quod intellectus agens nihil recipit ab intelligibilibus, sed magis formam suam eis tribuit, faciendo ea intelligibilia actu; intellectus autem possibilis e converso se habet», De Veritate, q. 20, a. 2, ad 5. «Intellectus agens est potentia activa. Ipsum etiam inteligibile in actu facit intellectum in potentia esse intellectum in actu: et sic intellectus possibilis est potentia passiva. Non autem ponitur quod intellectus agens sit subiectum habitum, sed magis intellectus posibilis: unde et ipsa potentia quae habitui naturali subiicitur, magis videtur esse potentia passiva quam activa», De Veritate, q. 16, a. 1, ad 13/24. «Unde non oportet quod si intellectus agens non indiget habitu quod intellectus possibilis habitu non indigeat», De Veritate, q. 20, a. 2, ad 5./12.

$23 \ll$ Species intelligibilis id quod in ea formale est, per quod est intelligibilis actu, habet ab intellectu agente, qui est potentia superior intellectu possibili; quamvis id quod in ea materiale est, a phantasmatibus abstrahatur», $D e$ Veritate, q. 18, a. 8, ad 3/6. Y más adelante: «quamvis autem tota anima sit perfectior quam intellectus agens non tamen quaelibet alia potentia animae est nobilior intellectu agente», De Veritate, q. 20, a. 2, ad 5. El problema, que se arrastra desde el Comentario a las Sentencias y que tendrá largo recorrido, no es el de la superioridad del agente sobre el posible, que es muy clara en los textos, sino el considerar al agente precisamente como una «potencia».

24 De alguna manera admite TOMÁs DE AQUINo que el intelecto deba ponerse a nivel de acto de ser cuando dice: «intellectus quoad actum essendi est forma animae, sed quoad actum intelligendi est e converso», De Veritate, q. 10 , a. 8 , ad 13 . 
en otros lugares llama «sustancias separadas» ${ }^{25}$. 2) El conocimiento de los transcendentales deriva del conocimiento abstractivo generado por intelecto agente ${ }^{26} .3$ ) El entendimiento agente no conoce nada al margen de la abstracción ${ }^{27}$.

Evidentemente estas tesis suscitan también arduos problemas. Por ejemplo: 1) ¿El entendimiento agente conoce sólo las formas abstraídas? 2) ¿Cómo se llega al conocimiento de los trascendentales desde la abstracción llevada a cabo por virtud del entendimiento agente?, ¿es que acaso pertenecen a la misma instancia cognoscitiva las formas abstraídas y los trascendentales?, ¿los transcendentales son objetos abstractos?, ¿seguro que se llega a ellos por abstracción? 3) Si el entendimiento agente no conoce nada al margen de la abstracción, ¿cómo conocemos al propio entendimiento posible y agente?

De otra manera, si se admite que el entendimiento agente es lo superior del alma, y sabemos que lo tenemos, ¿cómo lo sabemos? No puede ser merced a lo inferior del alma, porque lo inferior no puede iluminar lo superior; ¿tal vez es el alma misma la que conoce aquello superior de ella? Y si es así, entonces ¿qué unión o distinción media entre el alma y el intelecto agente? Si se responde que la índole del alma es ser cognoscitiva en virtud del intelecto agente, se está defendiendo que el conocer está a nivel de ser en el hombre. Por otra parte, ¿cómo conocemos otras realidades que no son sensibles: el intelecto posible, sus actos, hábitos, la voluntad, sus actos, sus virtudes, los hábitos innatos, Dios, etc.? Pero no apresuremos respuestas y recorramos pacientemente las obras tomistas a fin de lograr mayor esclarecimiento de las dificultades suscitadas.

\section{EL INTELECTO AGENTE EN LA SUMA CONTRA LOS GENTILES}

Del tratamiento del entendimiento agente en la Suma Contra los Gentiles el balance que podemos sacar estriba en que Tomás de Aquino mantiene, al menos, las siguientes tesis: 1) Es una «potencia» del alma ${ }^{28}$. 2) Su acción precede a la del entendimiento posible: «la acción del intelecto agente sobre los fantasmas precede a la recepción del intelecto posible» ${ }^{29}$. 3) Se sigue admitiendo la función abstractiva del intelecto agente ${ }^{30}$, que actúa al modo factivo ${ }^{31}$, como el

25 «Intellectus autem agens non facit intelligibilia formas separatas quae sunt ex se ipsis intelligibiles, sed formas quas abstrahit a phantasmatibus, et ideo huiusmodi sunt, quae primo intellectus noster intelligit», In Boetii De Trinitate, 1, 1, 3, co, 3/14.

26 «uamvis illa quae sunt prima in genere eorum quae intellectus abstrait a phantasmatibus, sint primo cognita a nobis, ut ens et unum, non tamen oportet quod illa quae sunt prima simpliciter (como Dios), quae non continentur in ratione proprii obiecti, sicut et ista», Summa Contra Gentes, 1, 1, 3, ad 3/2.

27 «Huiusmodi autem naturaliter cognita homini manifestantur ex ipso lumine intellectus agentis, quod est homini naturale, quo quidem lumine nihil manifestatur nobis, nisi inquantum per ipsum phantasmata fiunt intelligibilia in actu», Ibidem, 3, 6, 4, co, 2/4.

28 «Est igitur in anima intellectiva virtus activa in phantasmata, faciens ea intelligibilia actu: et haec potentia animae vocatur intellectus agens. Est etiam in ea virtus quae est in potentia ad determinatas similitudines rerum sensibilium: et haec est potentia intellectus possibilis», Ibidem, 1. II, cap. 77, n. 2 .

29 Ibidem, 1. II, cap. 77, n. 3.

30 «Intellectus agens non facit intelligibilia nisi phantasmata. Ergo nec intellectus possibilis movetur ab aliis intelligibilis nisi a speciebus a phantasmatis abstractis», Summa Contra Gentes, 1. II, cap. 60, n. 19. «Sic (en acto) est in intellectu possibili, et est abstractum a materialibus conditionibus per intellectum agentem», Ibidem, 1. II, cap. 73, n. 9/11. «Abstrahere formas universales a phantasmatibus est in intentione nostra, non solum in intentione agentis remoti. Igitur oportet in nobis ponere aliquod proximum principium talis effectus. Hoc autem est intellectus agens», 1. II, cap. 76, n. 15. «Intellectus agens facit species intelligibilis actu, inquantum abstrahit eas», Ibidem, 1 . II, cap. 82, n. 3 .

31 Aquí TOMÁs DE AQUINo emplea la palabra «factivus». Anteriormente comparaba el intelecto agente respecto de las especies como el hábito de arte respecto de las formas artificiales: «Comparatur enim intellectus agens ad species intelligibilis receptas in intellectu possibili, sicut ars ad formas artificiales quae per artem ponuntur in materia: ut patet ex exemplo Aristotelis in III De Anima», Ibidem, 1. II, cap. 76, n. 19. 
hábito de arte sobre lo que con éste se produce. 4) Activa al posible: «ya que la potencia no se reduce al acto sino por el acto... el intelecto posible se reduce al acto por el intelecto agente, que está en acto» ${ }^{32}$.

Otras tesis interesantes son: 5) Es connatural con nosotros: «nada prohibe atribuir la acción del intelecto agente a la misma luz inteligible connatural en nosotros ${ }^{33}$. 6) Se parece más al hábito que a la potencia ${ }^{34}$, pero en sentido estricto no es un hábito cognoscitivo, sino un acto que se distingue de la privación y de la potencia. 7) El intelecto agente no es sustancia separada $^{35}$, sino algo del alma, tesis que avala con el testimonio de Aristóteles. 8) El posible y el agente son concordes con la sustancia del alma. 9) En esta vida no podemos conocer a las sustancias separadas por el intelecto agente, aunque tras esta vida las podrá conocer, ya que su Iuz «es la semejanza en el alma de la luz intelectual que existe en las sustancias separadas» ${ }^{36} .10$ ) La última felicidad del hombre no consiste en el conocimiento de las sustancias separadas por el intelecto agente.

Todavía hay más: 11) El intelecto agente se asimila al ser sustancial del hombre: «si por la virtud intelectiva es necesario que el mismo entender del intelecto agente sea el entender del hombre, esto no puede ser a menos que de la sustancia del intelecto agente y de la sustancia del hombre se haga uno según el ser; pues es imposible que si son dos sustancias diversas según el ser, que la operación de una sea la operación de otra. Así pues, el intelecto agente será uno según el ser con el hombre. Pero no según el ser accidental: puesto que ya no sería el entendimiento agente sustancia, sino accidente... Queda, pues, que el intelecto agente sea uno con el hombre según el ser sustancial. Así pues, o bien será el alma humana o parte de ella, y no alguna sustancia separada» ${ }^{37}$. 12) El carácter instrumental de los primeros principios respecto del intelecto agente ${ }^{38}$. 13) Tanto el entendimiento posible como el agente subsisten tras la muerte $^{39}$, y pueden conocer cuando el alma se separe del cuerpo. 14) No es necesario que el

\section{Ibidem, 1. II, cap. 78, n. 10.}

33 Ibidem, 1. II, cap. 77, n. 4.

34 «Necesse est et in anima esse has differentias. Et huiusmodi quidem, scilicet quod in anima est sicut materia, est intellectus (possibilis) in quo fiunt omnia intelligibilia. Ille vero, qui in anima est sicut efficiens causa, est intellectus in quo est omnia facere (scilicet intelligibilia in actu), idest intellectus agens, qui est sicut habitus, et non sicut potentia. Qualiter autem dixerit intellectum agentem habitum, exponit subiungens quod est sicut lumen: quodam enim modo lumen facit potentia colores esse actu colores, inquantum scilicet facit eos visibiles actu: hoc autem circa intelligibilia attribuitur intellectui agenti», Ibidem, I. II, cap. 78, n. 2. Y un poco más adelante: «Aristotelis dicit quod intellectus agens est sicut habitus quod est lumen. Habitus autem non significatur ut aliquid per se existens, sed alicuius habentis. Non est igitur intellectus agens aliqua substantia separatim per se existens, sed est aliquid animae humanae», Ibidem, 1. II, cap. 78, n. 5. Y más abajo: «non autem intelligitur littere Aristotelis ut habitus dicatur esse effectus intellectus agentis», Ibidem, n. 6. El entendimiento agente en Aristóteles «accipitur habitus secundum quod contra privationem et potentiam, sicut omnis forma et actus potest dici habitus», Ibidem, n. 7.

35 «i intellectus agens est quaedarn substantia separata, sequeretur quod intelligere non sit operatio naturalis homini. Et sic homo non poterit definiri per hoc quod est intellectivus aut rationalis», Ibidem, 1. II, cap. 76, n. 17.

36 Ibidem, 1: III, cap. 45, n. 9.

37 Ibidem, 1. III, cap. 42, n. 7.

38 «Es necesario que el intelecto agente se refiera a los principios naturalmente conocidos por nosotros o como el agente al instrumento o como la forma a la materia», Ibidem, l. III, cap. 43, n. 2. Y añade: «sunt autem quaedam in nobis facta intellecta in actu naturaliter, non ex studio aut ex nostra voluntate, sicut prima intelligibilia. Haec autem facere intellecta actu non contingit per intellectum in habitu, per quem fiunt intellecta in actu ea quae scimus ex studio: sed magis sunt initium intellectus in habitu. Unde et habitum horum intelligibilium ab Aristotele, in VI Ethicorum, intellectus dicitur. Fiunt autem intellecta in actu per solum intellectum agentem».

$39 \ll$ Sed intellectus agens facit actu intelligibilia: ut ex praemissis patet. Cum igitur intelligibilia actu, inquantum huiusmodi, sint incorruptibilia, multo fortius intellectus agens erit incorruptibilis. Ergo et anima humana, cuius lumen est intellectu agens, ut ex praemisis patet», Ibidem, 1. II, cap. 79, n. 9. 
intelecto agente active a la voluntad, o que emplee para ello un hábito innato, pues ésta es activada por el posible ${ }^{40}$.

¿Problemas suscitados en este tratado, además de los enumerados en las obras precedentes a la Summa Contra Gentes? 1) ¿El entendimiento agente ilumina exclusivamente lo sensible? O de otro modo: ¿acaso el único modo posible de conocer del intelecto agente es por medio de la formación de las especies? 2) ¿Todo lo que conoce el posible es en sentido estricto «abstraído» por el agente?, ¿le ayuda el agente al posible en otros tipos de conocer que no son «abstractivos»?, ¿le ayuda directamente el intelecto agente, o se sirve para ello de instrumentos? 3) ¿Desde luego que la ayuda del entendimiento posible sirve en orden a la activación de la voluntad, pero basta con ello para activarla?, ¿no tendrá que ver en esa activación el intelecto agente?, ¿directamente o a través de algún instrumento? Evidentemente proponerle objetos como buenos es atraer a la voluntad desde fuera, pero todavía no es moverla desde dentro. Por tanto, ¿requiere la voluntad de otro principio para salir de su pasividad nativa? $\mathrm{Y}$ en caso afirmativo, ¿cuál? Veamos si en obras posteriores Tomás de Aquino resuelve estas cuestiones.

\section{EL INTELECTO AGENTE EN LAS CUESTIONES DISPUTADAS DE ANIMA}

Comienzan estas disputas académicas distinguiendo en el alma humana entre aquello de ella que es acto y aquello otro que es potencia ${ }^{41}$; buen marco para sospechar dónde encuadrar al entendimiento agente y dónde al posible. Si se recapitula la doctrina tomista sobre el entendimiento agente de todo este tratado se puede decir que se encuentran algunas novedades doctrinales de peso, formuladas, además, académicamente, porque estamos ante un escrito de sesgo universitario. Junto a ello, Tomás de Aquino en estas Cuestiones Disputadas sigue manteniendo otras tesis precedentes como las siguientes.

1) El papel de abstraer $^{42}$ del intelecto agente, es decir, su función de $a c t o^{43}$, pero no directamente sobre el posible, sino sobre las especies ${ }^{44}$.2) El carácter instrumental del hábito de los primeros principios respecto de él: «es necesario que el intelecto agente preexista al hábito de los primeros principios como su causa; ya que los principios se comparan al entendimiento agente como ciertos instrumentos suyos, ya que por ellos, hace a las demás cosas inteligibles en acto» ${ }^{45}$. 4) La luz del intelecto agente es don de Dios, pues se lo describe como

40 «Operatio autem propria hominis est intellectu agens, qui facit species intelligibiles, a quibus patitur quodammodo intellectus possibilis, qui factus in actu, movet voluntatem», Ibidem, 1. II, cap. 76, n. 20 .

41 «Anima humana, cum sit subsistens, composita est ex potentia et actu. Nam ipsa substantia animae non est suum esse sed comparatur ad ipsum ut potentia ad actum. Nec tamen sequitur quod anima non possit esse forma corporis: quia etiam in aliis formis id quod est ut forma ut actus in comparatione ad unum, est ut potentia in comparatione ad aliud; sicut diaphanum formaliter advenit aëri tamen est potentia respectu luminis», $Q . D . D e$ Anima, q. un., a. 1 , ad 6.

42 «Actio intellectus agentis consistit in abstrahere a materia», Ibidem, q. un, a. 6, ad 5/11.

43 «Necesse est igitur quod intelletus agens comparetur ad intelligibilia speculata sicut principale agens ad instrumentum, et sicut ut forma ad materiam, vel actus ad potentiam; semper enim quod est perfectius duorum, est quasi actus alterius», Ibidem, q. un., a. 16, co/40.

44 «Intellectus possibilis non potest reduci in actum cognitionis omnium naturalium per lumen solum intelectus agentis, sed per aliquam superiorem substantiam, cui actu adest cognitio omnium naturalium. Et si quis recte consideret, intellectus agens, secundum ea quae Philosophus de ipso tradit non est activum respectu intellectus possibilis directe, sed magis respectu phantasmatum, quae facit intelligibilia actu, per qua intellectus possibilis reducitur in actum quando aspectus eius inclinatur ad inferiora ex unione corporis. Et eodem ratione quando aspectus eius est ad superiora post separationem a corpore, fit in actu per species actu intelligibiles quae sunt in substantiis superioribus, quasi per agens proprium. Et sic talis cognitio est naturalis», Ibidem, q. un., a. 18, ad 11.

45 Ibidem, q. un., a. 5, co/170. 
«cierta virtud participada de alguna sustancia superior, a saber, de Dios. Por lo cual el Filósofo dice que el intelecto agente es como cierto hábito y luz; y en el Salmo IV se dice: 'impresa está sobre nosotros la luz de tu rostro, Señor ${ }^{46}$. 5) El agente es más noble y superior que el posible. 7) Por último, si la última felicidad humana es cognoscitiva: «la última bienaventuranza o felicidad del hombre consiste en su operación nobilísima, que es entender, cuya perfección última es necesario que sea por el hecho de que nuestro intelecto se una a su principio activo ${ }^{47}$, en ella debe estar implicado el intelecto agente.

En cuanto a las nuevas averiguaciones de este escrito, contamos, en resumen, con: 1) Que de algún modo podemos llegar al conocimiento de las sustancias separadas, aunque ello sea a través de la abstracción, pues algún conocimiento de ellas debemos tener; de lo contrario, sería absurdo incluso plantearnos si existen. 2) Que el agente es acto en el alma, y el posible es potencia. En efecto, «se requiere en nosotros un principio activo propio, por el cual lleguemos a ser inteligentes en acto, y éste es el intelecto agente» ${ }^{48}$, y «nos hace inteligentes en acto» ${ }^{49}$. 3) En el hombre las diversas acciones cognoscitivas duales son concurrentes ${ }^{50} .4$ ) Agente y posible son algo del alma: «es necesario que exista en nosotros algún principio formal por el que recibamos los inteligibles, y otro por el que los abstraigamos. Así pues, uno y otro son algo en nosotros ${ }^{51}$. 5) El conocer del posible es, a distinción del conocer del agente, intermitente. El agente es cognoscitivo cuando concurre con el posible. 6) A la unión de entendimiento agente y posible la llama intelecto en acto. 7) La luz de la fe y de la profecía se añaden sobrenaturalmente a la luz natural del intelecto agente ${ }^{52}$, no a la del posible, asunto tan importante para la teología como olvidado ${ }^{53}$, porque si la fe y la profecía son nuevos modos de conocer, ello denota que el intelecto agente debe ser cognoscitivo.

Pero de las precedentes observaciones también surgen dudas, esto es, cuestiones planteadas y dificultades a resolver. Así: 1) El problema de poseer cierto conocimiento de las sustancias separadas radica en si el acceso cognoscitivo a ellas deriva de la abstracción o se trata de un conocer distinto. 2) Si el agente es acto del alma, ¿cómo podrá ser una «potencia» de ella? 3) $\mathrm{Si} \mathrm{entendimiento} \mathrm{agente} \mathrm{y} \mathrm{posible} \mathrm{son} \mathrm{dos} \mathrm{instancias} \mathrm{cognoscitivas,} \mathrm{¿cómo} \mathrm{aunar} \mathrm{las} \mathrm{diver-}$ sas dualidades cognoscitivas humanas, o cómo son concurrentes éstas? 4) $\mathrm{Si}$, por un lado se dice que el agente en el alma es como acto, y por otro se dice que es algo de ella ¿cómo entender este «algo»?, o también, ¿si es el acto del alma, cómo se dice que es «algo» de ella?, ¿acaso podrá ser una «potencia» de ella? Pero si es una "potencia» ¿cómo se dice de él que es «acto»?

Añadamos algunos otros interrogantes: 5) ¿Seguro que el tema del hábito de los primeros principios, instrumento del intelecto agente, se conoce por abstracción? 6) Si el hábito de los primeros principios es instrumento del entendimiento agente, ¿cómo puede serlo si en otros es-

46 «Est etiam in anima invenire quandam virtutem activam immaterialem, quae ipsa phantasmata a materialibus conditionibus abstrahit; et hoc pertinet ad intellectum agentem, ut intellectus agens, sit quaedam virtus participata ex aliqua substantia superiori, scilicet Deo», Ibidem, q. un., a. 5, co/147.

47 Ibidem, q. un., a. $5, \mathrm{co} / 80$.

48 Ibidem, q. un., a. $5, \mathrm{co} / 70$.

49 «Intellectus autem agens est qui facit nos intelligentes in actu», Ibidem, q. un., a. 5, co/6.

50 «Intellectus enim in actu comprehendit et intellectum possibilem et intellectum agentem. Et hoc solum animae est separatum et perpetuum et inmortale, quod continet intellectum agentem et possibilem, nam ceterae partes animae non sunt sine corpore», Ibidem, q. un, a. 5, ad 4.

51 Ibidem, q. un.m a. 5, co/115.

52 «Cum possuerimus intellectum agentem esse quandam virtutem participatam in animabus nostris; velut lumen quoddam, necesse est ponere aliam causam exteriorem a qua illud lumen participetur. Et hanc dicimus Deum, qui interius docet; in quantum huiusmodi lumen animae infundit, et supra huiusmodi lumen naturale addit, pro suo beneplacito, copiosus lumen ad cognoscendum ea ad quae naturalis ratio attingere non potest, sictut est lumen fidei et lumen prophetiae», Ibidem, q. un., a. 5, ad 6.

53 Cfr. mi artículo «Fides y persona» en Anuario Filosófico, (1999), pp. 737-811. 
critos se ha admitido que es hábito del posible?, ¿acaso lo es de los dos?, ¿cómo lo será? Y si en caso de que ahora se admita que es sólo instrumento del agente, ¿cómo lo es? 7) ¿Cómo es posible que se llame acto o intelecto en acto a algo que surge de la unión de un elemento potencial, como es el entendimiento posible? Como se puede apreciar, las preguntas más altas de la teoría del conocimiento salen a colación con la lectura de estos pasajes. Intentemos resolverlas abordando la lectura de las obras más maduras de Tomás de Aquino.

\section{EL INTELECTO AGENTE EN EL COMPENDIO DE TEOLOGÍA}

En esta obra Tomás de Aquino precisa el significado de sus expresiones entendimiento en hábito y entendimiento en acto: «cuando el intelecto posible ya es perfecto por las especies inteligibles, se llama intelecto en hábito, puesto que tiene ya las especies inteligibles de tal manera que puede usarlas cuando quiera, a medio camino entre la pura potencia y el acto perfecto. Pero cuando tiene las predichas especies en acto completo, se llama intelecto en acto» ${ }^{54}$. Para Tomás de Aquino el acto u operación inmanente parece superior al hábito. Con todo, mantiene en otras obras que el hábito es lo último de la potencia ${ }^{55}$, es decir, lo perfecto, lo que la lleva a su culminación. Otra indicación interesante en este pasaje radica en que es inherente al hábito hacer uso de él cuando se quiera; tesis en clara deuda con Averroes ${ }^{56}$.

En el Compendio de Teología se añade acerca del intelecto agente respecto de los escritos precedentes, en síntesis, lo que sigue: 1) Es, junto con el posible, como forma del hombre (forma hominis): «es necesario que tanto el intelecto posible como el intelecto agente se unan a este hombre como forma, y así es necesario que uno y otro se multipliquen en número según el número de los hombres. Además, es necesario que el agente y el paciente sean proporcionados entre sí, como la forma y la materia... Y por ello es por lo que a cada potencia pasiva responde una potencia activa de su género. Pues el acto y la potencia son de un género. Pero el intelecto agente se compara al posible como la potencia activa a la pasiva... Por tanto, es necesario que ambos sean de un género. Así pues, como el intelecto posible no es según el ser separado de nosotros, sino unido a nosotros como forma, y se multiplica según la multitud de los hombres..., es necesario también que el intelecto agente sea algo unido a nosotros formalmente, y que se multiplique según el número de los hombres» ${ }^{57}$.

2) Es accidente del alma, puesto que es una «potencia» suya y, por tanto, inhiere en ella. Con todo, añade que intelecto agente «es como la luz intelectual de la que el alma participa, a imitación de las sustancias intelectuales superiores» ${ }^{58}$. Esto marca una oscilación en el planteamiento tomista; vacilación que se agudiza cuando se acaba concluyendo que las potencias del alma son «principios de operaciones del alma... Pero unas están en el alma como en su principio y en su sujeto, ya que sus operaciones son del alma sin órgano corporal, y de este modo son las potencias de la parte intelectivas 59 .

Por otra parte, los problemas que estas formulaciones conllevan son variados. Por ejemplo. 1) Si agente y posible son como la forma del hombre, ¿informan directamente al cuerpo a pesar de carecer de soporte orgánico? Y si no lo informan, ¿cómo se informa el cuerpo? 2) Si son formas accidentales y, consecuentemente, no coinciden con el ser del alma, ¿qué queda en el alma por encima de estas «potencias» qué actúa como acto respecto de ellas? 3) Además, 
¿cómo se puede decir del intelecto agente que sea una «potencia» si es acto? Veamos si recurriendo a la explicación que Tomás de Aquino da de la composición real de los ángeles se pueden resolver, aunque sea por analogía, estos intrincados problemas humanos.

\section{EL INTELECTO AGENTE EN LAS CUESTIONES DISPUTADAS DE SPIRITUALIBUS CREATURIS}

En este escrito se nos recuerda el papel abstractivo del intelecto agente: «fue necesario poner alguna virtud que hiciese a los inteligibles en potencia ser inteligibles en acto, abstrayendo las especies de las realidades de la materia y de las condiciones individuantes; y esta virtud se llama intelecto agente» ${ }^{60}$, y ello «porque (Aristóteles) no ponía a las naturalezas de las realidades sensibles subsistir sin materia, de modo que fueran inteligibles en acto; y por eso era necesario existir alguna virtud que las hiciese inteligibles en acto, abstrayendo de la materia individual; y esta virtud se llama intelecto agente ${ }^{61}$. Y más adelante: «nada prohibe que en la misma esencia del alma se encuentre el intelecto posible, que está en potencia respecto de las especies que se abstraen de los fantasmas, y el intelecto agente, que abstrae las especies de los fantasmas» ${ }^{62}$. Acepta asimismo que el conocimiento abstractivo es irrestricto ${ }^{63}$.

Se admite también, como en obras precedentes, que el intelecto agente es don creatural divino: «decimos que la luz del intelecto agente, de la que habla Aristóteles, es impresa en nosotros inmediatamente por Dios» ${ }^{64}$. Y más adelante: «es llamado por Aristóteles luz recibida en nuestra alma por Dios» ${ }^{65}$.

Se sigue admitiendo, como precedentemente, que el intelecto agente es «algo del alma, y que se multiplica según la multitud de almas y hombres» ${ }^{66}$. Y se añade algo ya sabido, a saber, alguna breve referencia a la inmaterialidad del entendimiento agente y a su vinculación con el alma humana como la siguiente: «las potencias que están en la sola sustancia del alma como en su sujeto son el intelecto agente, el posible y la voluntad ${ }^{67}$. Pero, como se puede apreciar, esto no constituye ningún nuevo añadido temático.

Con todo, podemos preguntar ¿qué nuevas claves sobre el intelecto agente se encuentran en las Cuestiones Disputadas sobre las Criaturas Espirituales? La respuesta es que, fundamentalmente, éstas:

1) Una prueba, no de demostración, sino de mostración de la existencia de Dios: «es necesario que por encima del alma humana exista algún intelectò del que dependa su entender (el del intelecto agente) ${ }^{68}$, y para fundamentar eso aporta tres razones: 1 ) «Porque todo lo que conviene a alguien por participación, es primero sustancialmente en alguien». 2) «porque es necesario que previo a todo móvil se encuentre algo inmóvil». 3) «Porque aunque en uno y lo

60 De Spiritualibus Creaturis, q. 9, co/153.

61 Ibidem, q. 10, co/2.

62 «Nihil prohibet in eadem essentia animae inveniri intellectum possibilem, qui est in potentia respectu specierum quae abstrahuntur a phantasmatibus, et intellectum agentem, qui abstrahit speciem a phantasmatibus», Ibidem, q. 10, ad 4/24.

63 «Intellectus noster non habet terminum respectu intelligibilium sibi connaturalium, quae a sensibus abstrahuntur; sed tamen terminum habet, quia circa superiora intelligibilia, quae sunt substantiae separatae, deficit», Ibidem, q. 10 , ad $7 / 20$.

64 «Unde dicimus, quod lumen intellectus agentis, de quo Aristóteles loquitur, est nobis immediate impressum a Deo, et secundum hoc discernimus vero a falso, et bonum a malo», Ibidem, q. 10, co/155.

65 Ibidem, q. $10, \mathrm{co} / 180$.

66 Ibidem, q. 10, co/160.

67 \&Potentiae vero que sunt in sola substantia animae sicut in subiecto, sunt intellectus agens et possibilis et voluntas», q. un., a. 11, ad 20/7.

68 Ibidem, q. 10, co/ 13. 
mismo la potencia sea previa al acto, sin embargo, de modo simple el acto precede a la potencia en otro; y de modo semejante, antes de todo lo imperfecto es necesario que exista otro perfecto». Obviamente tal intelecto del que participa el intelecto agente humano es el divino.

2) Si en las Cuestiones Disputadas De Anima se decía que la luz de la fe y de la profecía radican en el intelecto agente (cfr. q. un., a. 5, ad 6), aquí se añade que también la luz de la gracia y de la gloria se otorgan como dones a él: «es propio de Dios iluminar a los hombres imprimiéndoles la luz natural del intelecto agente, y sobre ésta, la luz de la gracia y de la gloria» ${ }^{69}$. Pues bien, ¿qué puede significar para el entendimiento agente ser iluminado? De acuerdo con lo que acabamos de presentar, no puede significar otra cosa que ser elevado cognoscitivamente. A eso obedecen, por ejemplo, la fe (lumen fidei) y la gloria (lumen gloriae). Estas dos no son sino la elevación del intelecto agente, una en esta vida, otra luego. De modo que Tomás de Aquino admite que el entendimiento agente es cognoscitivo, a menos que se niegue de la fe y la gloria, por ejemplo, que sean conocimiento, asunto que, desde luego, no es tomista, ni por supuesto cristiano.

3) Por último, para Tomás de Aquino, los primeros principios prácticos también son iluminados por el intelecto agente, como había asegurado desde el De Veritate respecto de los primeros principios especulativos (cfr., q. 18, a. 7, co). En efecto, sostiene que por él juzgamos no sólo de lo verdadero y de lo falso, sino también de lo bueno y de lo malo ${ }^{70}$. Ello indica que no sólo es instrumento del intelecto agente el hábito de los primeros principios teóricos, sino también el de los primeros principios prácticos o sindéresis. Por eso, de lo moral juzgamos por medio de los primeros principios prácticos, que «se captan por la luz del intelecto agente participado de Dios, como también los primeros principios de las ciencias especulativas» ${ }^{71}$.

¿Problemas mantenidos en esta obra? Al menos éstos: 1) El llamado «intelecto en acto» entiende siempre, pero ¿entiende siempre el intelecto agente?, ¿por qué? La respuesta de Tomás de Aquino atraviesa la siguiente cuestión. 2) En una respuesta a las objeciones se lee: «no hay que decir que el intelecto agente entienda separadamente del intelecto posible, sino que el hombre entiende por uno y otro» ${ }^{72}$. Pero si eso es así, ello indica que el intelecto agente no conoce al margen del posible o sin el concurso con él, que es tanto como decir que no es acto al margen de la potencia, lo cual es un tanto comprometido, pues bien sabe Tomás de Aquino que la potencia no se explica al margen del acto, pero que, en cambio, el acto es explicable sin la potencia.

3) Si el intelecto agente ilumina los primeros principios (especulativos y prácticos), y lo propio del intelecto agente es iluminar especies, ¿acaso son los primeros principios teóricos especies?, ¿tal vez lo son los prácticos? Pero si las especies derivan de la abstracción ¿cómo pueden ser primeros principios asuntos que son derivados? ¿no hay aquí una visión en exceso $o b$ jetualista? Además, los primeros principios son realmente fundantes mientras que las especies están al margen de fundar algo real, pues están desvinculadas de cualquier causalidad real, ya que no son otra cosa que objetos conocidos en cuanto tales. Por tanto, ¿cómo podrán ser los primeros principios especies? Como se aprecia, esto impone una gran dificultad a aquellos que admiten que los primeros principios son mentales y no reales extramentales. Además, esta mentalidad será objetualista o logicista, pero no realista. Sin embargo, como de la relación de los primeros principios y el intelecto agente se trata en la próxima obra, pasemos a los textos relevantes de ella sobre este tema.

69 Ibidem, q. 10, ad 1.

70 Cfr. lbidem, q. 10, co/185.

71 Ibidem, q. 10, ad 9.

72 «Non est autem dicendum quod intellectus agens seorsum intelligat ab intellectu possibili: sed homo intelligit per utrumque», Q. D. De Spiritualibus Creaturis, q. 10, ad 15. 


\section{EL INTELECTO AGENTE EN EL COMENTARIO AL DE ANIMA DE ARISTÓTELES}

Tras mostrar de nuevo la existencia del intelecto agente y su papel abstractivo; nos recuerda Tomás de Aquino en este comentario que por la luz del intelecto agente conocemos los primeros principios ${ }^{73}$, pero distingue al intelecto agente del hábito innato de los primeros principios, «porque el intelecto, que es el hábito de los primeros principios presupone alguna cosa ya entendida en acto, a saber, el término de los principios, por cuyo conocimiento conocemos los principios. Y así se seguiría que el intelecto agente no haría todas las cosas inteligibles en acto, como dice aquí el Filósofo» ${ }^{74}$.

Comenta también las cuatro notas que Aristóteles atribuía al intelecto agente, tres de ellas comunes al posible, a saber, separable, impasible e inmixto, y una propia y distintiva suya: «en acto según su sustancia» ${ }^{75}$. Derivado de lo precedente, deduce la superioridad jerárquica del entendimiento agente sobre el posible. Añade que tanto el posible como el agente son partes del alma ${ }^{76}$. Reitera que el entendimiento agente, como virtud activa que es, es «cierta participación de la luz intelectual de las sustancias separadas» ${ }^{77}$. Si el agente y el posible permanecen tras la muerte, dado que estarán separados del cuerpo, ya no conocerán como ahora, sino de otro modo, «pero cómo conozcan entonces, no es de la presente intención discutirlo» ${ }^{78}$, porque la traza de esta obra es filosófica, no de exposición de la teología de la fe.

En conclusión, como resumen de la lectura de esta obra por lo que toca a nuestro tema se pueden colegir las siguientes deducciones: 1) Un ser inteligente como es el hombre, si no tuviera el principio del conocimiento en sí mismo, sería constitutivamente imperfecto. Luego, si la naturaleza no hace nada en vano (tampoco la humana), el intelecto agente es la raíz de todo conocer y «algo unido» a uno. 2) Tomás de Aquino nota cierta unión natural entre el entendimiento agente y el posible, pero tal unión debe ser investigada más atentamente. 3) Si el agente y el posible permanecerán siempre, ello permite entenderlos como un proyecto de futuro histórico y posthistórico.

Pero este comentario también nos ofrece, al menos, este problema centrado en la última tesis tomista: si el alma humana, merced al intelecto agente y al posible es un proyecto de futuro histórico y posthistórico, como ningún proyecto está clausurado, ello permite preguntarse acerca de la finalidad del proyecto. Una primera respuesta negativa surge inmediata: no puede ser su fin nada susceptible de ser conocido suficièntemente en esta vida, porque ello no es el fin del alma, sino más bien al revés, el fin de tales realidades es el que sean conocidas por el alma. De modo que el fin debe trascender todo aquello que alcanzamos a conocer ahora según el modo ordinario de conocerlo.

Por otra parte, entre el De Anima y el De Unitate Intellectus contamos con algunas referencias aisladas al entendimiento agente en otros escritos del corpus tomista. Por ejemplo, en los Comentarios a los Analíticos y a la Física de Aristóteles, Tomás de Aquino sigue aceptando su papel de abstraer las especies ${ }^{79}$. En las Cuestiones Disputadas De Virtutibus se lee

73 «Homo enim per lumen intellectus agentis, statim cognoscit actu prima principia naturaliter cognita», Ibidem, 1. II, lc. 11, n. 15.

74 In De Anima, 1. III, Ic. 10, n. 2.

75 Ibidem, l. III, lc. 10, n. 5.

76 «Quod sint partes animae, vel potentiae, et non aliquae substantiae separatae», Ibidem, n. 5.

77 Ibidem, n. 12.

78 Ibidem, n. 18.

79 «Intellectum agentem, qui facit intelligibilia in actu per abstractionem universalium a singularibus», In Posteriores Analiticorum, 1. II, lc. 20, n. 12/13. «Aristotelis autem opinio est, quod scientia fit in anima per hoc quod species intelligibiles, abstractae per intellectum agentem, recipiuntur in intellectu possibili, ut dicitur in III De Anima», In Physicorum, 1. VII, lc. 6, n. 8/26. 
que el intelecto agente es, al margen de las funciones vegetativas, la única potencia del alma que es activa $a^{80}$, pero esta descripción implica que lo sigue considerando como «potencia». Por su parte, en el opúsculo De Substantiis Separatis sigue sosteniendo que el intelecto agente es más noble que el posible ${ }^{81}$.

\section{EL INTELECTO AGENTE EN EL OPÚSCULO SOBRE LA UNIDAD DEL INTELECTO CONTRA LOS AVERROISTAS}

La expresión «contra averroistas» que se añade en el título de esta obra es, manifiestamente, muy indicativo de aquello que se va a tratar, a saber, de la pluralidad de intelectos humanos frente a la unicidad del mismo que propugnaban los seguidores de Averroes. Este estudio del entendimiento comprende, aunque el texto no contenga muchas referencias al «intelecto agente», tanto al entendimiento posible como al agente. En el escrito Tomás de Aquino expone minuciosamente el sentido auténtico de los textos de Aristóteles, haciendo ver que por «separado», «perpetuo» e «impasible», hay que entender que el entendimiento posible y el agente son «algo del alma, que es acto del cuerpo; pero de suerte que el entendimiento no tiene ningún órgano corporal, como lo tienen las otras potencias del alma» ${ }^{82}$. Son potencias o partes del alma, pero que carecen de órgano corpora ${ }^{83}$. El entendimiento posible y el agente no son, por tanto, ni una sustancia separada ni Dios.

Lo separado, es - según Aristóteles - lo que verdaderamente es; y sólo esto es inmortal y perpetuo. «Lo que verdaderamente es» se dice en el sentido de que es lo diferencial del hombre, y ello se atribuye no sólo al entendimiento posible, como algunos pensaron, sino también al agente ${ }^{84}$. Por eso añade que «no hay que decir tampoco que esto (el que el entendimiento sea separado del alma) se refiere sólo al entendimiento en cuanto se contrapone al (entendimiento) agente, según lo sueñan algunos. Pues esto lo afirmó Aristóteles antes de probar que el entendimiento se divide en posible y en agente: por lo cual entiende aquí por entendimiento a la parte en común (alma intelectiva), en cuanto contiene al entendimiento agente y al posible» ${ }^{85}$.

A continuación precisa más el sentido aristotélico de «separado»: «así como (Aristóteles) antes dijo que uno y otro entendimiento, es decir, posible y agente, estaban separados, sin embargo, aquí dice que no son o existen separados. Pues es separado, en cuanto no es acto del órgano, mientras que no es separado, en cuanto es parte o potencia del alma, que es acto sustancial del cuerpo» ${ }^{86}$. Y más adelante explicita el sentido aristotélico de «proviene de fuera»: «pero como el alma intelectiva tiene operaciones independientes del cuerpo, por lo mismo todo su ser no consiste en la concreción respecto de la materia, y por consiguiente no puede decirse que proviene o es sacado de la materia, sino más bien que proviene de un principio extrínseco» ${ }^{87}$.

En este punto, Tomás de Aquino expone, como en otras obras, su acuerdo o desacuerdo con ciertos comentadores aristotélicos. Tengámoslos en cuenta resumidamente aquí: «con evidencia se desprende de las precedentes palabras de Temistio que sostiene que es parte del alma

80 «Inter potentias animae non sunt activae nisi intellectus agens», Q. D. De Virtutibus, q. 1, a. 3, ad. 5.

81 «Intellectus agens est nobilior intellectu possibili, qui recipit species intelligibiles actu ab intellectu agente factas, non autem ipsae res naturales cognitae», De Substantiis Separatis, 16/87.

82 Ibidem, cap. 1/465.

83 «Potentia quae est intellectus nullius corporis actus est, quia eius operatio non fit per organum corporale», De Unitate Intellectus, cap. 1/497.

84 Ibidem, cap. 1/548.

85 Ibidem, cap. 1/260. Cfr. asimismo: cap. 1/ 615.

86 Ibidem, cap. $1 / 700$.

87 Ibidem, cap. 1/775. 
no sólo el entendimiento posible, sino también el entendimiento agente, como también se desprende que ésta es la doctrina de Aristóteles» ${ }^{88}$. De Teofrasto no llegaron los libros hasta Tomás de Aquino, pero de lo que Temistio declara de aquél saca las conclusiones de que para Teofrasto el entendimiento es connatural a nosotros a la par que proviene del exterior. De Alejandro indica que fue mal interpretado por Averroes, y que sostenía que el entendimiento posible, potencia del alma carente de órgano, estaba en potencia respecto de los inteligibles.

En cuanto a Avicena, Tomás de Aquino indica que éste sostuvo que el entendimiento es una virtud del alma, siendo ésta forma del cuerpo. Distinguía Avicena entre el entendimiento activo, que precisa siempre del cuerpo, y el contemplativo, que no siempre ni totalmente precisa de él. Pero el alma humana no es ninguno de ellos, sino que es lo que tiene estas virtudes. Añadía que el alma, en cuanto a su ser intelectiva, no es forma del cuerpo ni precisa de órgano. Por su parte, Algacel sostuvo que el alma humana la otorga el dador a aquello que es un equilibrio perfecto de elementos, y. que consta de dos virtudes: la operante y la especulativa (entendimiento), siendo así que la operación de ésta última no se ejerce por ningún órgano corporal. En suma, Tomás de Aquino se preocupa de dejar, claro frente a Averroes y los averroistas, que tanto los autores latinos, como los griegos y árabes arriba mencionados, concuerdan en afirmar que el sentido auténtico de las palabras de Aristóteles es que el entendimiento es parte, potencia o virtud del alma, y que ésta es forma del cuerpo.

A distinción del parecer de Averroes, para quien el intelecto posible era una sustancia separada que se expresaba a través del entender de los hombres, Tomás de Aquino señala que es propio de cada hombre. Declara insostenibles asimismo las opiniones de quienes afirman que el entendimiento se une al cuerpo como motor, o la de aquéllos que creen que el entendimiento no es el acto del cuerpo, sino que lo es el mismo acto de entender. Revisa también la opinión de quienes mantienen que el entendimiento es uno para todos. Declara que, evidentemente, eso no se puede predicar del entendimiento agente según los textos de Aristóteles, puesto que para el Estagirita el entendimiento agente es algo que está en el alma, y es comparable a la luz, pues, de lo contrario, «en vano puso Aristóteles un entendimiento agente que convirtiera a los inteligibles en potencia en inteligibles en acto» ${ }^{89}$. En suma, la interpretación de Averroes, tanto de Aristóteles como de Temistio y de Teofrasto, es para Tomás de Aquino errónea.

Como se aprecia, Tomás de Aquino sigue manteniendo el papel abstractivo del entendimiento agente ${ }^{90}$. Añade también que es el principio natural de la ciencia en cada quien ${ }^{91}$. Se cierra el opúsculo concluyendo que «ni el entendimiento agente, al que Aristóteles se refiere, es uno, el cual ilumina; ni tampoco es uno el intelecto posible que es ilustrado o iluminado, sino que es verdad que el principio de la iluminación o ilustración es uno (único), es decir, alguna .sustancia separada, a saber, Dios, según los católicos, o la inteligencia última, según Avicena» ${ }^{92}$.

\section{EL INTELECTO AGENTE EN LA SUMA TEOLÓGICA}

Tomás de Aquino explica la existencia del intelecto agente en esta obra suya, la más madura, con el mismo argumento que en sus primeros escritos, a saber, como nada pasa de la po-

88 Ibidem, cap. $\mathbf{I} / 60$.

89 Ibidem, cap. IV/ 195. Y más adelante añade: (Aristóteles) «de ipso intellectu possibili loquitur secundum id quod est proprium sibi, et secundum quod distinguitur ab agente», Ibidem, cap. IV/220.

90 «peciem lapidis... fit intellecta in actu per hoc quod species a rebus sensibilibus, mediantibus sensibus, usque ad phantasiam perveniunt, et per virtutem intellectus agentis species intelligibiles abstrahuntur, quae sunt in intellectu possibili», De Unitate Intellectus, 5/231.

91 «In discipulo est principium naturale scientiae, scilicet intellectus agens et prima principia per se nota», Ibidem, cap. V/ 255.

92 lbidem, cap. V, fin. 
tencia al acto sino por algo en acto, era necesario poner «alguna virtud por parte del intelecto, que hiciese los inteligibles en acto, por la abstracción de las especies de las condiciones materiales. Y esta es la necesidad de poner al intelecto agente ${ }^{93}$. Como se ve, sigue sosteniendo que lo propio del entendimiento agente es iluminar las especies de la sensibilidad favoreciendo la abstracción $n^{94}$. Además, al argumento inicial sobre la existencia del intelecto agente añade ahora otro muy relevante, a saber, que conocemos que existe en nosotros experiencialmente ${ }^{95}$.

Por otra parte, enseña que «cuando se dice que el intelecto agente es su acción, no es predicación por esencia, sino por concomitancia, ya que cuando su sustancia está en acto, inmediatamente, en cuanto depende de sí, se une a la misma acción. Lo cual no es propio del intelecto posible, que no tiene acciones sino tras ser hecho en acto ${ }^{96}$. Se admite, por tanto, una dualidad entre el intelecto agente y su acción. Es decir, se sigue respetando la distinción real en todo lo creado, pues la identidad es exclusivamente divina.

Admite, también, que el intelecto agente deriva de Dios, y que es algo del alma ${ }^{97}$. En efecto, nada prohibe que el intelecto agente, que participa del intelecto supremo, proceda de la esencia del alma, pues ésta está creada por él ${ }^{98}$. Por tanto, «si el intelecto agente es algo del alma, como cierta virtud de la misma, es necesario decir que existen múltiples intelectos agentes según la multitud de las almas, que se multiplican según la multitud de los hombres» ${ }^{99}$.

Reparemos ahora en algunos problemas suscitados a raíz de la lectura de los artículos de esta cuestión. Si bien se mira, parece que algunas de las respuestas de Tomás de Aquino no son del todo satisfactorias, y que, en consecuencia, conviene precisarlas. Vamos a considerar sólo los siguientes puntos:

1) Si el intelecto agente deriva de la esencia del alma (como potencia de ella que se dice que es), y dado que todas las potencias del alma pertenecen a la naturaleza humana, es decir, a lo común del género humano, se tiende a concebir que el entendimiento agente (a pesar de ser distinto en cada quién) debe tener el mismo diseño como potencia y la misma operatividad en todos los hombres, pues todo lo que pertenece a la naturaleza humana es de las mismas características para todo el género humano. Sin embargo, si el entendimiento agente no se entendiese como potencia sino como acto, e incluso como acto respecto del alma, no pertenecería a la naturaleza humana, a lo común, sino que equivaldría a la persona humana, a lo distinto e irreductible de cada quien. Con ello también se salvaría el que fuese uno en cada hombre (pues por él cada hombre es persona), pero se tendría una ventaja sobre la concepción precedente, a saber, que de este modo se vería claro que es acto, y en modo alguno se tendría necesidad de explicarlo como una potencia, ni por referencia a ninguna potencia.

2) Si el entendimiento agente es acto y se emplaza en el núcleo personal o acto de ser personal, es claro que el intelecto agente no puede tener primordialmente la tarea de abstraer, que

93 Summa Theologiae, I ps., q. 79, a. 3, co.

94 «Intellectus agentis est illuminare non quidem alium intelligentem, sed intelligibilia in potentia, inquantum per abstractionem facit ea intelligibilia actu. Ad intellectum autem possibilem pertinet esse in potentia respectu naturalium cognoscibilium, et quandoque fieri actu», Summa Theologiae, I ps., q. 4, ad 2/3. Cfr. asimismo: Ibidem, I ps., q. 44, a. 3, ad 3; q. 85, a. 1, ad 3; I ps., q. 87, 1 co; q. 87, a. 1, ad 2/6; q. 88, a. 1, co/109.

95 «In ipsa (anima) sit aliqua virtus derivata a superiori intellectu, per quam possit phantasmata illustrare. Et hoc experimento cognoscimus, dum percipimus nos abstrahere formas universales a conditionibus particularibus, quod est facere acto inteligibilia», Ibidem, I ps., q. 79, a. 4, co.

96 «Cum dicitur quod intellectus agens est sua actio, est praedicatio non per essentiam, sed per concomitantiam, quia cum sit in actu eius substantia, statim quantum est in se, concomitatur ipsam actio. Quod non est de intellectu possibili, qui non habet actiones nisi postquam fuerit factus in actu», Ibidem, I ps., q. 54, a. 1, ad 1.

97 Ibidem, I ps., q. 79, a. 4 co.

98 «Cum essentia animae sit inmaterialis, a supremo intellectu creata, nihil prohibet virtutem quae a supremo intellectu participatur, per quem abstrait a materia, ab essentia ipsius procedere, sicut et alias eius potentias», Ibidem, ad 5.

99 Ibidem, I ps., q. 79, a. 5, co. 
es común al género humano, es decir, algo común de la naturaleza humana, pues lo personal es lo distinto en cada uno. ¿No será que para esa función cada persona o intelecto agente se sirve de un instrumento innato similar para todos los hombres? Pero Tomás de Aquino sigue manteniendo hasta el final de su producción que la función propia del intelecto agente es abstraer $^{100}$. En suma, la deuda contraída con el legado de Aristóteles pesa demasiado en el corpus tomista. Con todo, si algunos descubrimientos del Estagirita son geniales, al Filósofo, más que seguirlo, hay que proseguirlo.

No acaba de decidirse Tomás de Aquino por emplazar el intelecto agente a nivel de acto de ser, a pesar de que escribe que «el entender... es respecto al intelecto en acto como el esse al ente en acto ${ }^{101}$, y si el intelecto agente es entender, en consecuencia... Sin embargo, ¿seguro que para Tomás de Aquino el intelecto agente es entender? Para él no lo es sin el concurso del posible. Pero ¿acaso todo conocimiento es abstractivo o derivado de la abstracción? Parece que Tomás de Aquino se inclina a pensar que sí, pues indica que el conocimiento de las causas físicas, por ejemplo, es debido al intelecto agente ${ }^{102}$. Y no sólo éstas, sino que también admite que el alma se conoce a sí misma a raíz de la abstracción ${ }^{103}$. Y si conocemos nuestra propia alma de ese modo, de seguro que se puede concluir que ese modelo sirve para explicar asimismo nuestro conocimiento de Dios. Pero si todo nuestro conocimiento divino es derivado de la abstracción, al final hay que rematar diciendo, como él admite, que de Dios sabemos más lo que no es que lo que es.

\section{CONCLUSIONES}

Dado que el bagaje tomista sobre el entendimiento agente, expuesto sucintamente en este trabajo, es tan amplio, es conveniente recopilar, en último extremo, todas las notas que Tomás de Aquino le atribuye. Se procede, pues, ahora a la exposición temáticamente ordenada (no cronológica), y sin reiteraciones, de esta síntesis doctrinal; y se opera según 4 apartados: a) Presentación de las tesis tomistas positivas defendidas sobre el intelecto agente a lo largo de su obra; b) Reunión de las tesis tomistas negativas sobre el entendimiento agente; c) Relación de cuestiones abiertas o interrogantes que ofrece el planteamiento tomista del entendimiento agente; d) Elenco de algunas propuestas de solución a las precedentes dificultades.

\section{A) Tesis positivas defendidas en el corpus tomista sobre el intelecto agente}

1) El entendimiento agente existe realmente en el hombre.

2) Es uno según el ser con el hombre. Pero según el ser sustancial, no según el ser accidental, puesto que ya no sería el entendimiento agente sustancia, sino accidente.

3) Es «algo», «parte», «potencia» «accidente» del alma; y, por ello, se funda (como el posible) en la esencia del alma.

4) Es una potencia humana sin soporte orgánico distinta del posible, pero se parece más al hábito que a la potencia (pues se distingue de la privación y de la potencia).

100 «Propria autem operatio intellectus agentis est facere species intelligibiles actu, abstrahendo eas a phantasmatibus, unde dicitur in III De Anima quod intellectus agens est quo est omnia facere», Summa Theologiae, III ps., q. 9, a. 4, co/16. «Sicut autem intellectus possibilis est quo est omnia fieri, ita intellectus agens est omnia facere», Ibidem, III ps., q. 12, a. 1, co/9. «Extrahere species intelligibiles a phantasmatibus sit quaedam naturalis actio hominis secundum intellectum agentem», Ibidem, III ps., q. 12, a. 2, co/35.

101 Summa Theologiae, I ps., q. 34, a. 1, ad 2. Cfr asimismo: Ibidem, I ps., q. 14, a. 1, co.

$102 \ll$ Ex virtute luminis intellectus agentis possit homo procedere ad intelligendum effectus per causas, et causas per effectus, et similia per similia, et contraria per contraria», III ps., q. 12, a. 1, ad 1 .

103 «(Anima) nec seipsam potest intelligere nisi inquantum fit actu intelligens per speciem a phantasmatibus abstractam, sic enim per actum suum intelligit seipsam», Summa Theologiae, I-II ps., q. 89, a. 2, co/11. 
5) Pertenece a esa parcela del alma que es separada, no dependiente del cuerpo y, por tanto, inmortal y perpetua.

6) Empieza a existir con el cuerpo (es connatural y originario en nosotros), pero sobrevive a él, y sigue conociendo cuando éste perece.

7) Es uno para cada hombre; personal, por tanto.

8) Es forma de nosotros (»forma nobis»). Pero es forma del cuerpo en un sentido distinto (principio finito) a como es principio de operaciones intelectuales (infinito).

9) Es luz cognoscitiva innata, y por él conocemos todo lo que podemos conocer: «y según esto discernimos lo verdadero de lo falso, y lo bueno de lo malo».

10) Es acto (principio activo propio) y, por tanto, previo y superior, respecto del posible (que es potencial).

11) Su acción le es concomitante, pero no existe identidad real entre él y su acción.

12) Procede de Dios: «luz impresa en nosotros inmediatamente por Dios». Es un desbordamiento en nosotros de la perfección divina. Es cierta participación de la luz intelectual de las sustancias separadas, en especial de Dios: «virtud derivada del intelecto superior».

13) Participa de Dios tanto natural como sobrenaturalmente (y según esto último, tanto la vida presente, por la fe, la profecía y la gracia, como en la futura, por la gloria).

14) El intelecto agente muestra la existencia de Dios (es necesario que por encima del alma humana exista algún intelecto del que dependa el entender del intelecto agente).

15) Los hábitos de los primeros principios (teóricos y prácticos) son un instrumento suyo: «los primeros principios prácticos se captan por la luz del intelecto agente..., como también los primeros principios de las ciencias especulativas».

16) Activa al posible mediante el hábito de los primeros principios.

17) Para conocer se sirve de la potencia cogitativa de la sensibilidad intermedia, potencia que dispone de los fantasmas.

18) Está en acto respecto de las especies sensibles, de las que abstrae, universaliza.

19) El conocimiento de los transcendentales deriva del conocimiento abstractivo generado por intelecto agente. lítica.

20) Gracias a él el hombre es libre y responsable, y por ello son posibles la ética y la po-

21) Tras la muerte ya no conocerá como ahora, sino de otro modo (»el alma separada tendrá un modo de entender diferente que el del alma unida»).

B) Tesis negativas defendidas en el corpus tomista sobre el intelecto agente.

1) El intelecto agente no es uno para todos los hombres.

2) Ni es sustancia separada ni es Dios.

3) Ni conoce directamente a las sustancias separadas ni a Dios en esta vida, aunque sí indirectamente, derivadamente de la abstracción.

4) No es autointencional o reflexivo.

5) No es susceptible de hábitos (innatos, adquiridos e infusos).

6) No es lo mismo que el hábito de los primeros principios.

7) Sin él el hombre no puede conocer nada.

8) No es subsistente, sino algo del alma.

9) La última felicidad del hombre no consiste en el conocimiento de las sustancias separadas por el entendimiento agente.

10) El que uno entienda mejor o peor que otro no se debe al entendimiento agente de cada uno, sino a la complexión de las potencias con soporte corporal de las que éste abstrae (imaginación, memoria, etc.).

11) No siempre conoce.

12) No actúa sin su concurrencia con el posible (para defender la unidad humana).

13) No activa directamente al posible, sino mediante las especies. 
14) No tiene como algo propio tener o dejar de tener especies, lo cual es propio del posible. El agente no tiene en sí ninguna especie inteligible.

15) No basta él sólo para activar al posible, pues la perfección del posible no se logra tampoco sin Dios. ble.

16) No activa a la voluntad ni directa ni indirectamente, pues ésta es activada por el posi-

\section{C) Cuestiones abiertas en el corpus tomista referidas al intelecto agente.}

1) ¿Cómo es posible que el agente sea en sentido estricto una «potencia» si está en acto desde el inicio?

2) ¿Cómo se puede admitir que los hábitos innatos no inhieran en el entendimiento agente, si «hábito» significa perfección, esto es, acto, y el posible nativamente es tamquam tabula rasa, a saber, pura potencia?

3) ¿Seguro que lo que es susceptible de conocer el intelecto agente se reduce sólo a lo sensible y a lo que se abstrae de aquello, o por el contrario, es capaz de saltar ese ámbito de asuntos cognoscibles? De otro modo, ¿cuál es en sentido estricto el «objeto» del entendimiento agente, es decir, su tema?

4) ¿Seguro que se llegan a conocer los transcendentales por abstracción?, ¿cómo?, ¿dependen de la misma instancia cognoscitiva las formas abstraídas y los trascendentales?

5) ¿Le ayuda el agente al posible en otros tipos de conocer que no son «abstractivos»? Y en casi afirmativo, ¿le ayuda directamente o se sirve de instrumentos?

6) Si sólo conocemos derivadamente de la abstracción, ¿cómo se admite que conocemos al propio entendimiento agente experiencialmente?, ¿es eso abstraer?, ¿se le conoce sólo por sus «efectos» abstractivos?

7) ¿Seguro que la activación del entendimiento posible es suficiente para activar a la voluntad? ¿Seguro que el entendimiento agente no es acto también respecto de la voluntad? Y si lo es, ¿cómo lo es: directa o indirectamente?

8) Si el entendimiento agente está abierto cognoscitivamente de modo natural a Dios, y, a distinción del entendimiento posible, es en acto, ¿por qué no estamos siempre conociendo intuitivamente a Dios? Es más, ¿por qué no somos conscientes de que siempre conocemos, siendo como somos conocimiento en acto?

9) ¿Es el entendimiento agente jerárquicamente distinto en cada hombre por naturaleza?, ¿lo es por elevación?, ¿por ambos?

10) Si son varios los modos de elevar al entendimiento agente es esta vida (gracia, fe, profecía) ¿no será que el entendimiento agente admite varios miembros, esto es, que no es simple, sino que admite dualidades?

11) ¿Cómo es posible que el entendimiento agente sea cognoscitivo sólo cuando concurre con el posible si es en acto? Cuando no concurre con el posible ¿respecto de qué es acto?

12) Si el hábito de los primeros principios es instrumento del entendimiento agente, ¿cómo puede serlo si en varios escritos se admite que es un hábito del posible?

13) ¿Cómo puede el intelecto agente informar al cuerpo a pesar de carecer de soporte orgánico?

14) Si es potencia o accidente del alma, ¿qué queda en el alma por encima del intelecto agente que pueda actuar como acto respecto de él?, ¿será acaso algún otro principio cognoscitivo que esté más en acto?, ¿no abre esto un proceso al infinito? Y si se responde que es la esencia del alma, ¿es esa esencia cognoscitiva en acto? Y si no, ¿cómo podemos conocer la esencia del alma?

15) ¿Qué es lo que está vinculado con el intelecto agente, los hábitos de los primeros principios (teóricos y prácticos), lo tematizado por éstos, o ambas realidades?

16) ¿Es el intelecto agente quién conoce directamente tales hábitos, o se sirve como de instrumento de algún hábito superior a aquéllos para tal menester? 
17) Si el intelecto agente ilumina los primeros principios (especulativos y prácticos), y lo propio del intelecto agente es iluminar especies, ¿acaso son los primeros principios (teóricos y prácticos) especies?, ¿cómo pueden ser primeros principios asuntos que son derivados de la abstracción? Y si son distintos y los ilumina a ambos, ¿cómo los discierne?

18) ¿Qué entiende Tomás de Aquino por la expresión: «el hábito de los primeros principios presupone alguna cosa ya entendida en acto, a saber, el término de los principios, por cuyo conocimiento conocemos los principios»?

19) $\mathrm{Si}$ el entendimiento agente es una potencia del alma, en rigor no se puede buscar en él la imagen y semejanza divina, puesto que Dios es acto; y por ello, tal potencia «no participará de nada superior», a saber, de Dios.

\section{D) Propuestas de solución a las cuestiones tomistas abiertas sobre el intelecto agente.}

1) El entendimiento agente es un acto que hay que hacerlo equivaler al acto de ser personal humano. No es, pues, ni sustancia ni accidente, ni algo ni parte del alma, ni potencia ni acto como hábito, sino acto como acto de ser personal.

2) Dispone desde el inicio de hábitos innatos (no de adquiridos o infusos); no es susceptible de hábitos adquiridos, pero sí de hacer crecer a los innatos, y es capaz, también, de admitir hábitos infusos que eleven a los innatos. Además, es susceptible de aceptar él mismo ser elevado en esta vida por la fe infusa (lumen fidei), y en la otra, por la gloria (lumen gloriae), aunque ninguna de las dos sea propiamente un hábito.

3) Los instrumentos suyos son los hábitos innatos (sindéresis, primeros principios, sabiduría).

4) No abstrae directamente, sino que se sirve de un instrumento: la sindéresis.

5) No activa directamente al posible, sino que se sirve de un instrumento: la sindéresis.

6) No es acto directamente respecto de la voluntad. Para activarla se sirve como de instrumento de un hábito innato: la sindéresis.

7) No se conoce natural y directamente a sí, sino que se sirve para ello de un instrumento, de un hábito innato: el hábito de sabiduría. Pero por ser éste un hábito, y, por tanto, inferior al acto del intelecto agente, no permite conocer íntegramente al intelecto agente.

8) Seguramente no nos damos cuenta de que el entendimiento agente es siempre luz cognoscitiva que busca su tema propio, porque lo que se llama conciencia (el darse cuenta) depende de instancias cognoscitivas humanas inferiores él y a su tema.

9) Los hábitos adquiridos en la razón o entendimiento posible son la «conciencia» de que tenemos actos racionales. La sindéresis es la «conciencia» de que tenemos inteligencia y voluntad. El hábito de sabiduría es la «conciencia» de que tenemos intelecto agente (y hábitos nativos), aunque no seamos conscientes por tal hábito del tema de del intelecto agente.

10) Lo que se vincula o dualiza como miembro inferior con el intelecto agente son los distintos hábitos innatos, no los temas de éstos. De otro modo, los hábitos innatos son las diversas dimensiones de la apertura del intelecto agente hacia lo inferior.

11) Los hábitos innatos no se dualizan directamente con el intelecto agente, sino a través del hábito de sabiduría.

12) El saber que disponemos nativamente del hábito de la sindéresis no depende directamente del intelecto agente, sino del hábito de sabiduría.

14) El saber que disponemos del hábito de los primeros principios no depende directamente del intelecto agente, sino del hábito de sabiduría.

15) El saber que disponemos del hábito innato de sabiduría depende enteramente del intelecto agente.

16) El hábito de sabiduría nos permite conocer parcialmente nuestro entendimiento agente, es decir, nuestro acto de ser personal.

17) El tema propio del intelecto agente es Dios, y por redundancia él propio intelecto agente, o si se quiere, el sentido personal que el entendimiento agente es ante Dios. 
18) Aunque el entendimiento agente está naturalmente abierto a Dios, no conocemos directamente la esencia de Dios, porque esa apertura significa más una búsqueda que un encuentro definitivo.

19) Aunque en la apertura cognoscitiva del intelecto agente a Dios está implícita la apertura de Dios al entendimiento agente, todavía no conocemos nuestro intelecto agente enteramente, es decir, tal como Dios lo conoce.

20) Lo que precede indica asimismo que esta vida no es la definitiva, y que le cabe al entendimiento agente un modo de conocer más propio y perfecto que el de la presente situación de búsqueda, a saber, el encuentro definitivo de Dios y de sí.

Juan Fernando Sellés Departamento de Filosofía

Universidad de Navarra 31080 Pamplona jfselles@unav.es 